Polymer Journal, Vol. 38, No. 11, pp. 1127-1136 (2006)

(C) 2006 The Society of Polymer Science, Japan

\title{
Molecular Structure, Crystallinity and Morphology of Polyethylene/Polypropylene Blends Studied by Raman Mapping, Scanning Electron Microscopy, Wide Angle X-Ray Diffraction, and Differential Scanning Calorimetry
}

\author{
Tsuyoshi Furukawa, ${ }^{1,2}$ Harumi Sato, ${ }^{1}$ Yasuo Kita, ${ }^{3}$ \\ Kimihiro Matsukawa, ${ }^{3}$ Hiroshi Yamaguchi, ${ }^{1}$ Shukichi OCHIAI, ${ }^{2}$ \\ Heinz. W. SIESLER ${ }^{4}$ and Yukihiro OZAKI ${ }^{1, \dagger}$ \\ ${ }^{1}$ School of Science and Technology, Kwansei Gakuin University, Gakuen, Sanda 669-1337, Japan \\ ${ }^{2}$ S. T. Japan Inc., Minaminakaburi, Hirakata 573-0094, Japan \\ ${ }^{3}$ Plastics Department, Osaka Municipal Technical Research Institute, Morinomiya, Joto-ku, Osaka 536-8553, Japan \\ ${ }^{4}$ Department of Physical Chemistry, University of Duisburg-Essen, D-45117 Essen, Germany
}

(Received June 7, 2006; Accepted August 8, 2006; Published September 21, 2006)

\begin{abstract}
The present study is aimed at investigating the molecular structure, crystallinity, and morphology of polyethylene (PE) and polypropylene (PP) blends by using Raman mapping, scanning electron microscopy (SEM), wide-angle X-ray diffraction (WAXD), and differential scanning calorimetry (DSC). In this study, three kinds of PEs, high-density polyethylene (HDPE), linear low-density polyethylene (LLDPE), and metallocene polyethylene (MEPE) were used. MEPE is one of the LLDPEs but its density is very low and its melt flow index (MFI) is very high. Blends of each PE and PP with a PP content ranging from 20 to $80 \mathrm{wt} \%$ with an increment of $20 \mathrm{wt} \%$ were prepared. Raman mapping images and SEM images show that the 80/20 blends of HDPE/PP and LLDPE/PP have similar dispersibility behavior and that only the $80 / 20$ blend of MEPE/PP shows a different behavior in this respect. For the 20/80 blends, the differences are not so large. For the Raman mapping, the intensity ratio of the two bands at 1128 and $974 \mathrm{~cm}^{-1}$ was used. The former is due to a symmetric $\mathrm{C}-\mathrm{C}$ stretching mode of all-trans $-\left(\mathrm{CH}_{2}\right)_{n}-$ groups of $\mathrm{PE}$ while the latter is assigned to a $\mathrm{CH}_{3}$ rocking mode of $\mathrm{PP}$. MEPE/PP blends yield quite different X-ray diffraction patterns compared to HDPE/PP and LLDPE/PP blends; the MEPE/PP blends show that with increasing MEPE content the crystalline size of PP become smaller. DSC curves of MEPE/PP show that the peak area changes linearly with the blending ratio and that the crystallization temperature does not change for any blend. These results mean that the density and MFI of PE influences the blend properties. [doi:10.1295/polymj.PJ2006056]

KEY WORDS Metallocene Polyethylene / Polypropylene / Polymer Blend / Raman Mapping /

Scanning Electron Microscopy / Wide Angle X-Ray Diffraction / Differential Scanning Calorimetry /
\end{abstract}

Polyethylene (PE) and polypropylene (PP) are two polymers of great industrial importance. ${ }^{1,2}$ They are two of the most widely used plastics. There are three major classes of PEs, high-density PE (HDPE), low-density PE (LDPE), and linear low-density PE (LLDPE). ${ }^{1}$ The basic difference among the three classes of PEs lies in the degree and regularity of branching. While HDPE has very few branches, LDPE is characterized by a larger branching with irregular branches at irregular intervals. LLDPE, on the other hand, is characterized by branches of regular length (two, four, or six carbon atoms) at regular intervals. These structural differences are directly reflected in the physical properties of these polymers, such as crystallinity and melting point. Recently, metallocene PE (MEPE) was introduced as a new family of PEs. ${ }^{3-6}$ MEPE is a kind of LLDPE. However, the synthesis method of MEPE is quite different from that of
LLDPE. They have quite different crystallinity, density, melt flow index (MFI), and distribution of molecular weight. The long chain branches of MEPE influence its rheological and thermomechanical properties. Several groups have studied the polymerization and synthesis using metallocene catalyst. ${ }^{3,4}$ However, there are few reports regarding the blends of MEPE having unique physical properties.

To improve the physical and mechanical properties of polymers, the copolymerization or blending with other polymers are performed. The contents of copolymer unit and the blending ratio influence the properties. Therefore, it is important to investigate the blends with various contents of copolymer unit and blending ratio. However, the copolymerization has more difficulty than the blending, so that the latter technique is often adopted. Polymer blends of PE and PP also show very attractive physical properties

${ }^{\dagger}$ To whom correspondence should be addressed (Tel: +81-79-565-8349, Fax: +81-79-565-9077, E-mail: ozaki@kwansei.ac.jp). 
such as crystallinity behavior. ${ }^{7-18}$ These studies were carried out by means of wide-angle X-ray diffraction (WAXD), ${ }^{10,16,17}$ differential scanning calorimetry (DSC), ${ }^{10-16}$ microscopy, ${ }^{12-16,18}$ and so on. Although the unit structures of $\mathrm{PE}$ and $\mathrm{PP}, \mathrm{CH}_{2} \mathrm{CH}_{2}$ and $\mathrm{CH}_{2}$ $\mathrm{CH}\left(\mathrm{CH}_{3}\right)$, respectively, are very similar to each other, $\mathrm{PE}$ and PP blend polymers are immiscible. ${ }^{7,11,12}$ Therefore, it is very interesting to investigate if $\mathrm{PE}$ and PP have some interactions or not in the PE/PP blends. It is also important to compare the structure, dispersibility, and physical properties among various kinds of PE/PP blends such as HDPE/PP and LLDPE/PP. The addition of a compatibilizer to a $\mathrm{PE} / \mathrm{PP}$ blend causes the enhancement of its toughness. ${ }^{7} \mathrm{Li}$ et al. reported that PP components crystallized isothermally are immiscible with HDPE and LDPE and are miscible with LLDPE. ${ }^{14}$

The purpose of the present study is to investigate the molecular structure, crystallinity, and morphology of the three kinds of PE/PP blends, HDPE/PP, LLDPE/PP, and MEPE/PP by using Raman spectroscopy, ${ }^{19-25}$ Raman mapping, ${ }^{26}$ scanning electron microscopy (SEM), ${ }^{24,25}$ WAXD, ${ }^{23,27}$ and DSC. ${ }^{25,27}$ Raman mapping enables simultaneous exploration of the morphology and molecular structure of the blends. ${ }^{26,28-31}$ SEM is a well-established method for morphological characterization and supports the Raman mapping results by microscope images. WAXD allows one to investigate the crystallinity of blends, and by use of DSC information about the crystallization can be obtained. Therefore, a combination of these techniques has allowed us to explore the morphology, structure, and physical properties of the $\mathrm{PE} / \mathrm{PP}$ blends comprehensively.

\section{EXPERIMENTAL}

\section{Materials}

The polymers used in this study were high density polyethylene, SUNTEC-HDJ 240 (Asahi Chemical Industry Co., Ltd.), linear low density polyethylene, UF-240 (Japan Polyethylene Co. Ltd.), metallocene polyethylene, KN KJ640 (Nihon Polychem. Ltd.), and polypropylene, GRAND-POLYPRO-J602WA (Grand Polymer Ltd.). The density $\left(\mathrm{g} / \mathrm{cm}^{3}\right)$, melt flow index (MFI) (g/10 min), crystallinity (\%), and melting temperature of the above HDPE, LLDPE, MEPE, and PP are summarized in Table I. The crystallinity and melting temperature $\left(T_{\mathrm{m}}\right)$ are estimated from DSC data. All blends were prepared by compounding HDPE, LLDPE, or MEPE with PP at $220^{\circ} \mathrm{C}$ in a twin-screw extruder, respectively. Melt blending was carried out using a co-rotating intermeshing twin-screw extruder (BT-30-S2-42L, PLABOR Co. Ltd.) with an $l / d$ of 42 (30 $\mathrm{mm}$ screw diameter) at barrel temperatures
Table I. Physical properties of HDPE, LLDPE, MEPE, and PP

\begin{tabular}{lcccc}
\hline & $\begin{array}{c}\text { Density } \\
\left(\mathrm{g} / \mathrm{cm}^{3}\right)\end{array}$ & $\begin{array}{c}\text { MFI } \\
(\mathrm{g} / 10 \mathrm{~min})\end{array}$ & $\begin{array}{c}\text { Crystallinity } \\
(\%)\end{array}$ & $\begin{array}{c}T_{\mathrm{m}} \\
\left({ }^{\circ} \mathrm{C}\right)\end{array}$ \\
\hline HDPE & 0.969 & 5.0 & 75.7 & 134.6 \\
LLDPE & 0.920 & 2.1 & 44.9 & 122.5 \\
MEPE & 0.880 & 30.0 & n.d. & n.d. \\
PP & 0.910 & 1.5 & n.d. & 148.2 \\
\hline
\end{tabular}

n.d.: not detected.

ranging from $160^{\circ} \mathrm{C}$ at the feed zone to $220^{\circ} \mathrm{C}$ at the metering and die zones. The rotation speed of the twin-screw was $60 \mathrm{rpm}$. Blending ratios of HDPE/ PP, LLDPE/PP, and MEPE/PP were 20/80, 40/60, $60 / 40$, and $80 / 20$, respectively.

\section{Raman Mapping}

The Raman spectra of PE/PP blends were measured with a Kaiser Optical Systems HoloLab5000 Raman spectrometer equipped with a CCD detector. An excitation wavelength at $532 \mathrm{~nm}$ was provided by a frequency doubled Nd/YAG laser, and the laser power at the sample position was typically $3 \mathrm{~mW}$. Raman scattered light was collected in a $180^{\circ}$ back scattering geometry. Raman data were collected at a spectroscopic resolution of $1.2 \mathrm{~cm}^{-1}$. The exposure time and number of accumulations were $10 \mathrm{~s}$ and 2 times, respectively. Raman spectra were collected from the surfaces of pellets that were obtained by cutting out the original samples. Raman mapping images were generated by measuring 100 Raman spectra for each sample with areas of $10 \mu \mathrm{m}^{2}$ in step sizes of $1 \mu \mathrm{m}$ (for $10 \times 10$ sample spots). The spatial resolution was better than a few micrometers (the size of the laser beam was $1 \mu \mathrm{m}$ ). The software used for creating the Raman mapping images was Origin 6.1.

\section{Scanning Electron Microscopy (SEM)}

To study the morphology of PE/PP blends, HDPE/ PP, LLDPE/PP, and MEPE/PP extruded blends were collected, fractured under liquid nitrogen, and then observed under a JEOL JSM-5800LVC scanning electron microscope.

\section{Wide-Angle X-Ray Diffraction (WAXD)}

WAXD data for PE/PP were measured at room temperature by use of a RIGAKU R-AXIS IV imaging plate diffractometer. $\mathrm{Cu} \mathrm{K} \alpha$ radiation (wavelength, $1.5418 \mathrm{~nm}$ ) from a RIGAKU Ultra-X18 rotating anode $\mathrm{X}$-ray generator was used as an incident $\mathrm{X}$-ray source $(40 \mathrm{kV}, 100 \mathrm{~mA})$. Grams/AI software was used for the curve fitting of WAXD data.

\section{Differential Scanning Calorimetry (DSC)}

DSC measurements were performed on a Perkin- 


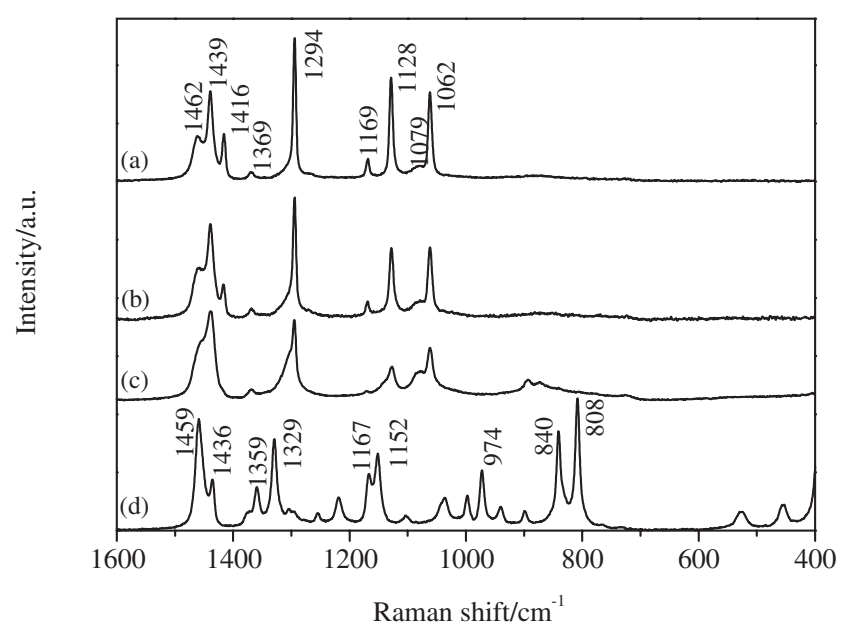

Figure 1. Raman spectra of HDPE, LLDPE, MEPE, and PP. (a): HDPE, (b): LLDPE, (c): MEPE, (d): PP.

Elmer Pyris6 system over a temperature range from 25 to $200^{\circ} \mathrm{C}$ at heating and cooling rates of $10^{\circ} \mathrm{C} /$ min. The samples (4-5 mg) were sealed in aluminum pans. The analysis of DSC curves for both the heating and cooling processes was carried out for the second run data.

\section{RESULTS AND DISCUSSION}

\section{Raman Mapping}

Figure 1 shows Raman spectra of HDPE, LLDPE, MEPE, and PP, respectively. These Raman spectra were not recorded in the micro-Raman mode but were measured as ordinary Raman spectra from pellets. Table II summarizes the band assignments made by referring to the Raman spectra of PE and PP reported previously. ${ }^{8,13}$ Not only PE but also PP have $-\left(\mathrm{CH}_{2}\right)-$ functionalities, so that most of bands appear in the Raman spectra in Figure 1. The crystallinity of PE can be investigated by Raman spectroscopy because some Raman bands are specific for the crystalline, amorphous, or anisotropic phases of PE. ${ }^{19,20}$ For example, it is well known that the Raman bands at 1416 and $1169 \mathrm{~cm}^{-1}$ are ascribed to the crystalline phase and that those at 1369 and $1079 \mathrm{~cm}^{-1}$ are assigned to the amorphous phase. ${ }^{19,20}$ One can also explore the conformation of $-\left(\mathrm{CH}_{2}\right)_{n}$ - by use of Raman spectroscopy because bands at 1462, 1294, 1128, and $1062 \mathrm{~cm}^{-1}$ are due to the all-trans- $\left(\mathrm{CH}_{2}\right)_{n}$ - structure while those at 1110 and $1079 \mathrm{~cm}^{-1}$ arises from the trans and gauche structures. ${ }^{19,20}$ The crystalline phase has an all-trans $\left(\mathrm{CH}_{2}\right)_{n}$-structure, so that the bands at $1462,1294,1128$, and $1062 \mathrm{~cm}^{-1}$ reflect the crystallinity, although they also contain a contribution from the anisotropic phases. The $1416 \mathrm{~cm}^{-1}$ band is also characteristic of crystallinity. ${ }^{19,20}$ The intensities of the bands at 1416 and $1128 \mathrm{~cm}^{-1}$ are much weaker
Table II. Wavenumbers $\left(\mathrm{cm}^{-1}\right)$ and Assignments of the Raman bands of PE/PP blends

\begin{tabular}{cccc}
\hline $\begin{array}{c}\text { Raman shift } \\
/ \mathrm{cm}^{-1}\end{array}$ & $\begin{array}{c}\text { Assignments } \\
(\mathrm{PE})\end{array}$ & $\begin{array}{c}\text { Assignments } \\
(\mathrm{PP})\end{array}$ & Features \\
\hline 1462 & $\mathrm{CH}_{2}$ bending & & Crystalline \\
1459 & & $\mathrm{CH}_{2}$ bending & \\
1439 & $\mathrm{CH}_{2}$ bending & & Crystalline \\
1436 & & $\mathrm{CH}_{2}$ bending & \\
1416 & $\mathrm{CH}_{2}$ bending & & Crystalline \\
1369 & $\mathrm{CH}_{3}$ wagging & & Amorphous \\
1359 & & $\mathrm{CH}_{3}$ wagging & \\
1329 & & $\mathrm{CH}_{2}$ twisting & \\
1294 & $\mathrm{CH}_{2}$ twisting & & all-trans $-\left(\mathrm{CH}_{2}\right)_{n}-$ \\
1169 & $\mathrm{CH}_{2}$ rocking & & Crystalline \\
1167 & & $\mathrm{C}-\mathrm{C}$ stretching $^{-}$ & Crystalline \\
1152 & & $\mathrm{C}-\mathrm{C}$ stretching & \\
1128 & $\mathrm{C}-\mathrm{C}$ stretching & & all-trans $-\left(\mathrm{CH}_{2}\right)_{n}-$ \\
1079 & $\mathrm{C}-\mathrm{C}$ stretching & & Amorphous \\
1062 & $\mathrm{C}-\mathrm{C}$ stretching & & all-trans $-\left(\mathrm{CH}_{2}\right)_{n}-$ \\
974 & & $\mathrm{CH}_{3}$ rocking & Crystalline \\
840 & & $\mathrm{CH}_{3}$ rocking & \\
808 & & $\mathrm{C}-\mathrm{C}$ stretching & Crystalline \\
\hline
\end{tabular}

in the Raman spectrum of MEPE than in those of HDPE and LLDPE. On the other hand, the intensity of the $1079 \mathrm{~cm}^{-1}$ band is much stronger in the Raman spectrum of MEPE than in those of HDPE and LLDPE. These results indicate that the crystallinity of MEPE in the blends is lower than that of HDPE and LLDPE. On the other hand, one can find some bands characteristic of PP. For example, a band at $808 \mathrm{~cm}^{-1}$ and bands at 974 and $840 \mathrm{~cm}^{-1}$ assigned to the $\mathrm{C}-\mathrm{C}$ stretching mode and the $\mathrm{CH}_{3}$ rocking mode, respectively, are characteristic of PP. ${ }^{19,20}$ These bands can be used for the characterization of crystallization and tacticity of PP. ${ }^{32,33}$ In the frequency regions where these bands are observed, no bands are observed for the three kinds of PEs. Therefore, by using the relative intensity of these bands one can estimate the relative content of $\mathrm{PP}$ in the blends.

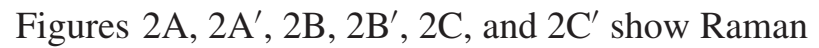
mapping images of an area of $10 \mu \mathrm{m}^{2}$ of HDPE/PP, LLDPE/PP and MEPE/PP with the PE content of 20 and $80 \mathrm{wt} \%$, respectively. To develop the maps, the intensity ratio of two bands at 1128 and $974 \mathrm{~cm}^{-1}$ $\left(\mathrm{I}_{1128} / \mathrm{I}_{974}\right)$ due to the $\mathrm{C}-\mathrm{C}$ stretching mode of PE and the $\mathrm{CH}_{3}$ rocking mode of PP, respectively, ${ }^{19,20}$ was employed. The band at $974 \mathrm{~cm}^{-1}$ is a good marker band for PP while it is difficult to find a band purely specific for PE that is free from the overlap of a PP band. We used the band at $1128 \mathrm{~cm}^{-1}$ since this band is relatively well separated from other bands. In the Raman mapping images, the darker parts and the lighter parts include more PP and PE component, respectively. 
(A)

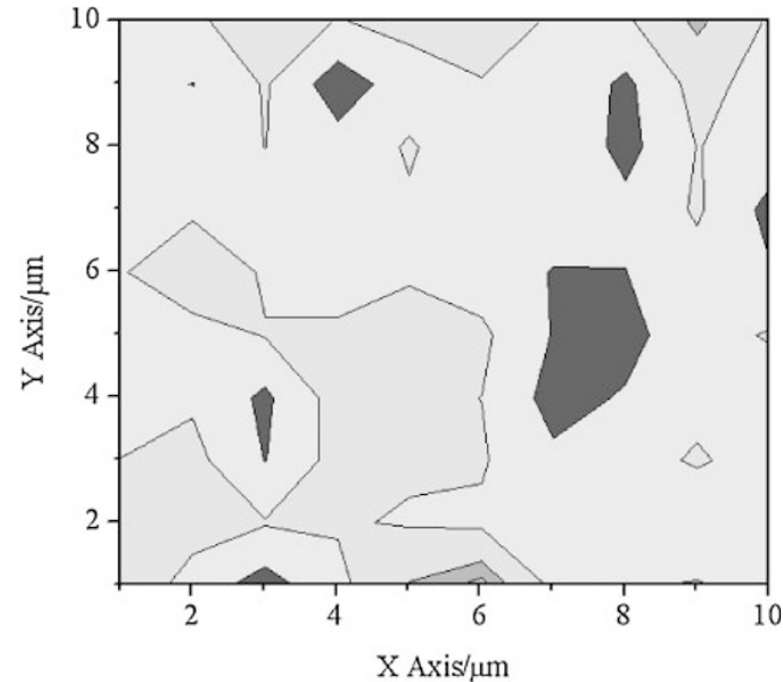

(B)

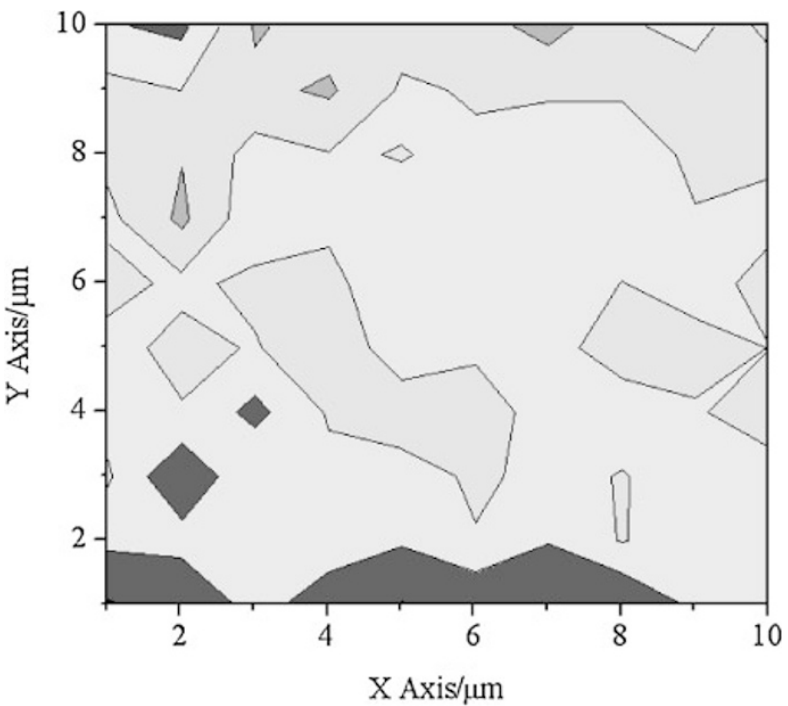

(C)

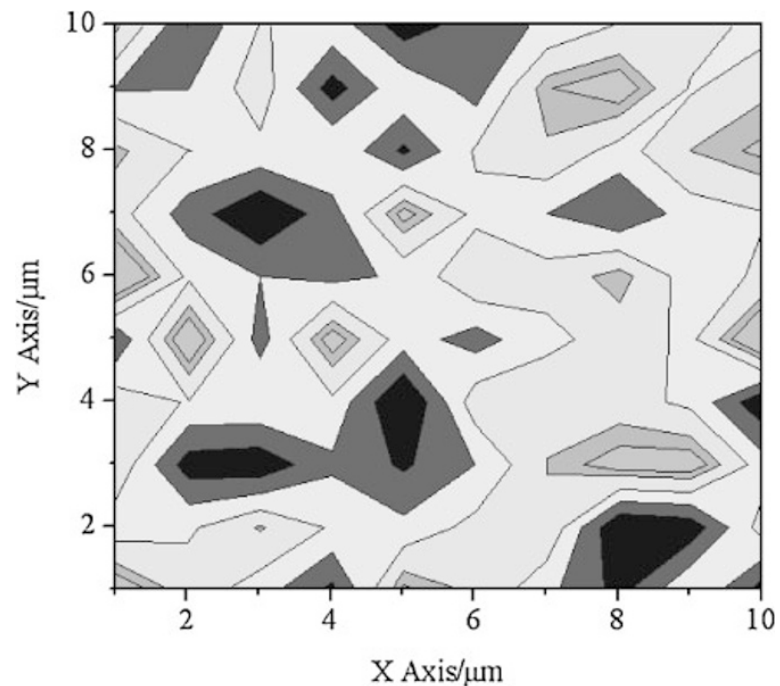

$\left(\mathrm{A}^{\prime}\right)$

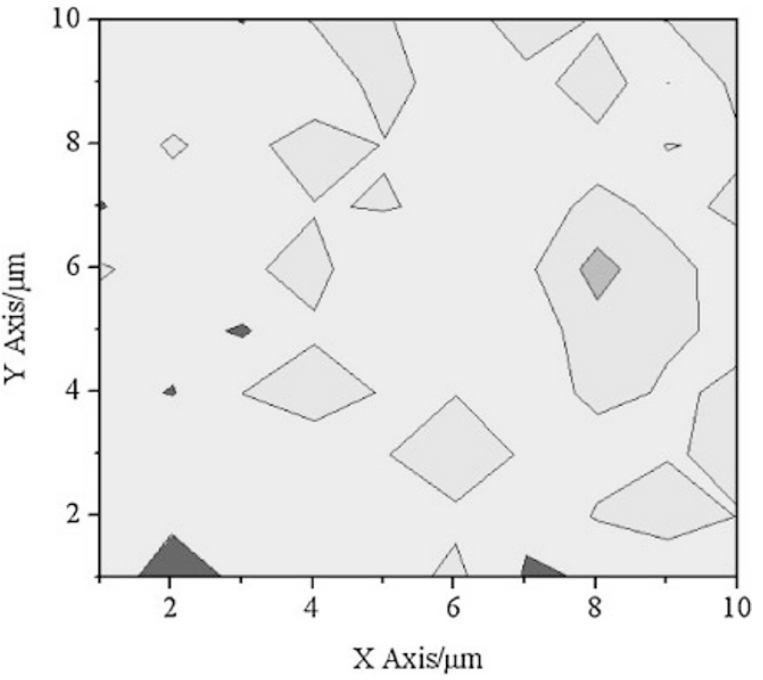

(B')

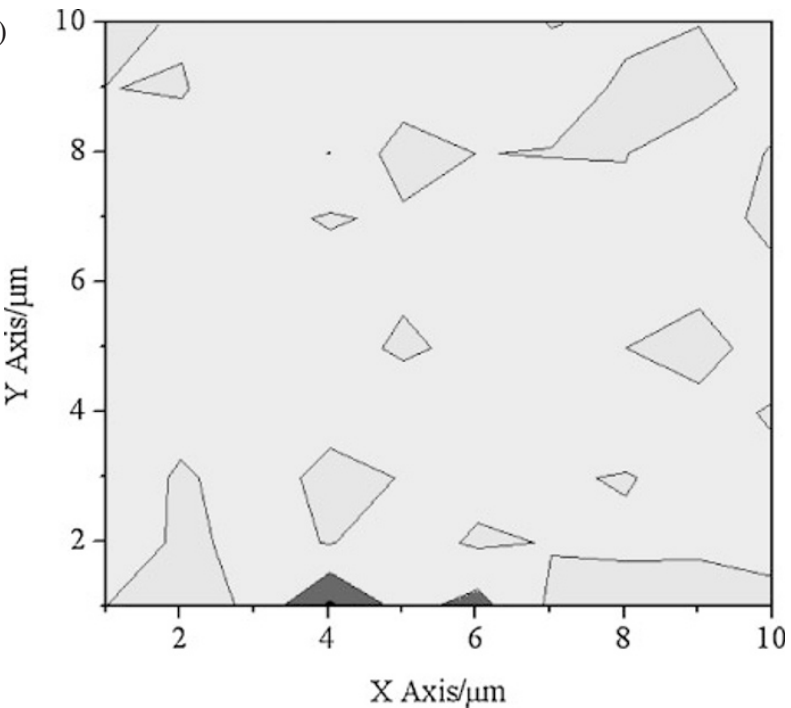

(C')

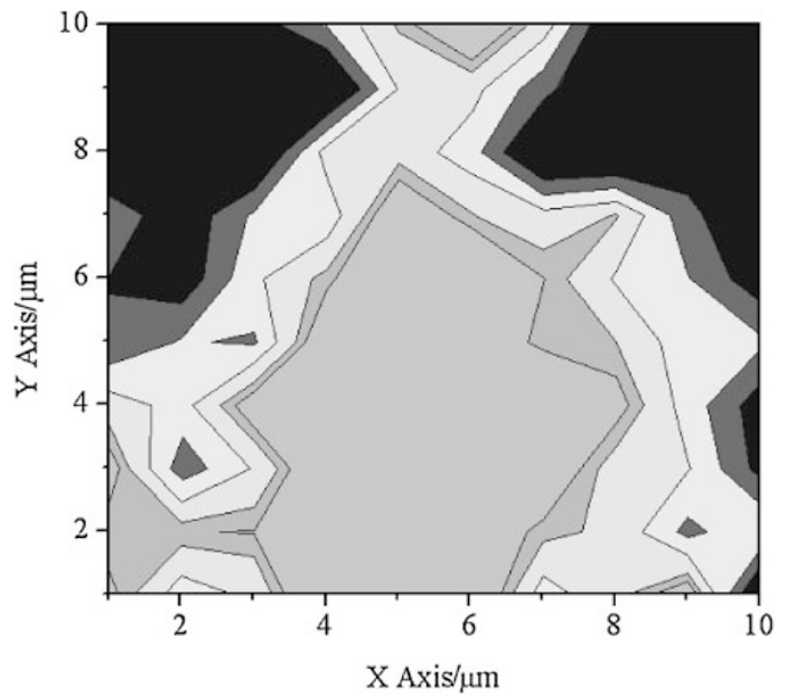

Figure 2. Raman mapping images of the area of $10 \mu \mathrm{m}^{2}$ for $20 / 80$ and $80 / 20$ blends of PE and PP. A: HDPE/PP blends (20/80), A': HDPE/PP blends (80/20), B: LLDPE/PP blends (20/80), B': LLDPE/PP blends (80/20), C: MEPE/PP blends (20/80), $\mathrm{C}^{\prime}$ : MEPE/PP blends (80/20). 


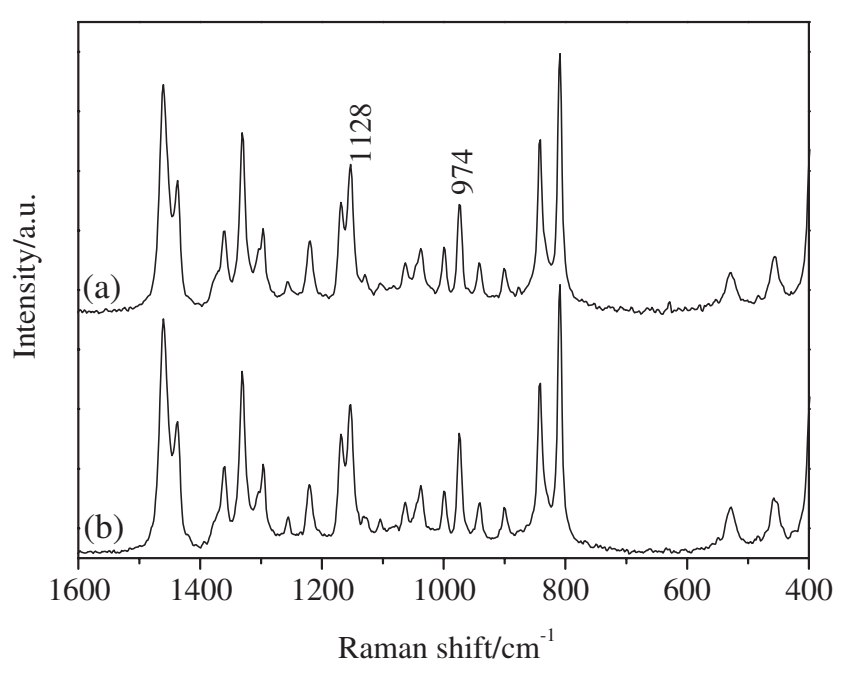

(A)

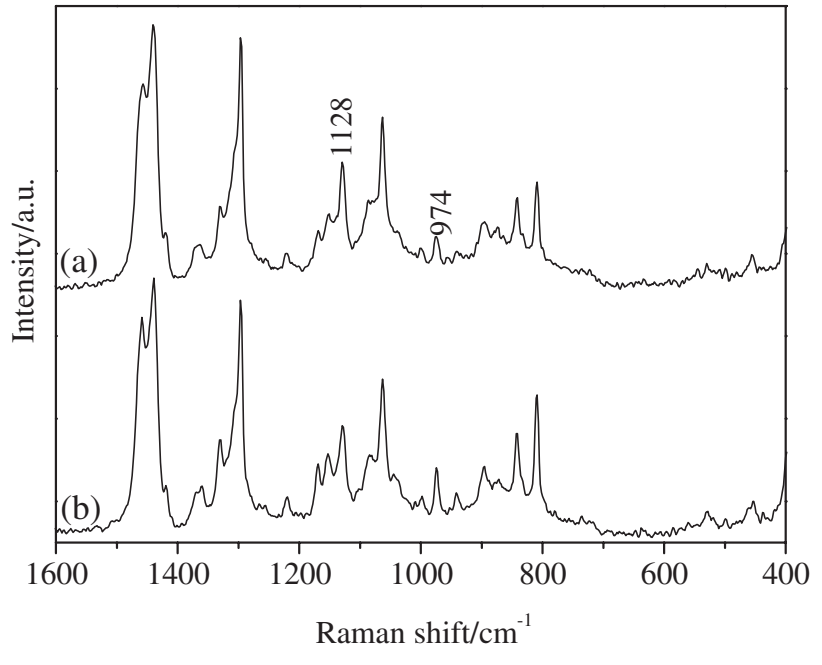

$\left(\mathrm{A}^{\prime}\right)$

Figure 3. Raman spectra of two positions with quite different colors in the mapping images of MEPE/PP blends for the 20/80 blend (A) and the 80/20 blend (A'). (a): PE-rich part, (b): PP-rich part.

The dispersibility of each component in polymer blends is affected by the melt viscosity ratio of components. Therefore, a comparison of MFI of each PE with $\mathrm{PP}$ is important. The MFI ratios of $\mathrm{PE}$ and $\mathrm{PP}$ in the HDPE/PP, LLDPE/PP, and MEPE/PP blends are $3.3,1.4$, and 20.0 , respectively. The ratio in the HDPE/PP blend is twice as large as that in the LLDPE/PP blend, and the ratio in the MEPE/PP blend is the largest among the three blends. As can be seen in Figure 2, the Raman mapping images of MEPE/PP are markedly different from those of HDPE/PP and LLDPE/PP in both blend ratios. High concentrations of PE appear black in each mapping image. Only the Raman mapping images of the MEPE/PP blends show a clear "sea-island" structure. The results of the Raman mapping images reveal that the MEPE/PP blends have an inhomogenous structure. Although MEPE is a kind of LLDPE, the results of Raman mapping of MEPE/PP blends are quite different from those of LLDPE/PP blends. It is very likely that the dispersibility of PE and PP depends on the MFI ratios, or on the kinds of PE. Three kinds of PE have different properties of branching. In other words, the degree and regularity of branching, which influence the dispersibility of PE and PP, are different.

The Raman spectra were collected from two positions for the Raman mapping images of the 20/80 and $80 / 20$ blends. Each two points in Figure 2 showed quite different color in the maps. In the 20/ 80 and 80/20 blends of HDPE/PP and LLDPE/PP, the two spectra are very similar to each other in terms of the relative intensities of the bands at 1128 and $974 \mathrm{~cm}^{-1}$ (data are not shown here). In contrast, the two spectra in MEPE/PP blends yield significantly different relative intensities of the bands, revealing that the two MEPE/PP blends have a heterogeneous structure (Figure 3).

\section{SEM}

Figure 4 shows SEM images of HDPE/PP, LLDPE/PP, and MEPE/PP with a PE content of 20 and $80 \mathrm{wt} \%$, respectively. Note that the SEM images of the MEPE/PP blends are clearly different from those of the HDPE/PP and LLDPE/PP blends for both blending ratios. The HDPE/PP and LLDPE/PP blends show good dispersibility for both blending ratios whereas the SEM images of the MEPE/PP blends show a typical "sea-island" structure. For the HDPE/ PP blends, the average size of HDPE particles in the 20/80 blend is $c a$. $0.5 \mu \mathrm{m}$, and the HDPE particles show good dispersibility. However, its size is smaller than the spatial resolution of Raman spectra. Therefore, it is difficult to obtain the same images between the Raman mapping and SEM for this blend. On the other hand, the average particle size of $80 / 20$ blend is hard to be estimated due to its good dispersibility. For the LLDPE/PP blends, both the 20/80 and 80/ 20 blends show good dispersibility, so that it is difficult to estimate the average particle size of each component. For the MEPE/PP blends, the average size of MEPE in the 20/80 blend is $c a .1 \mu \mathrm{m}$, and that of PP in the $80 / 20$ blend is over $3 \mu \mathrm{m}$. The dispersibilities of these blends are not good, so that each particle size can be estimated. The SEM results are also in good agreement with the conclusions drawn from the Raman mapping images.

\section{WAXD}

Figure 5 shows the resolution of the reflection pattern of the HDPE, LLDPE, MEPE, and PP in the angle 
(A)

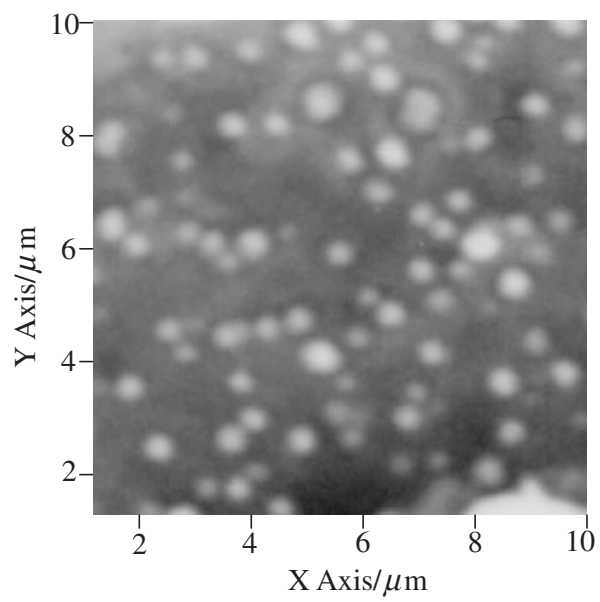

(B)

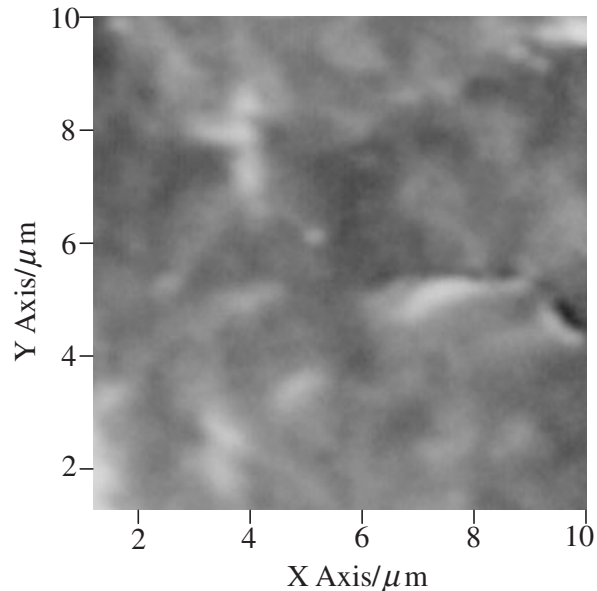

(C)

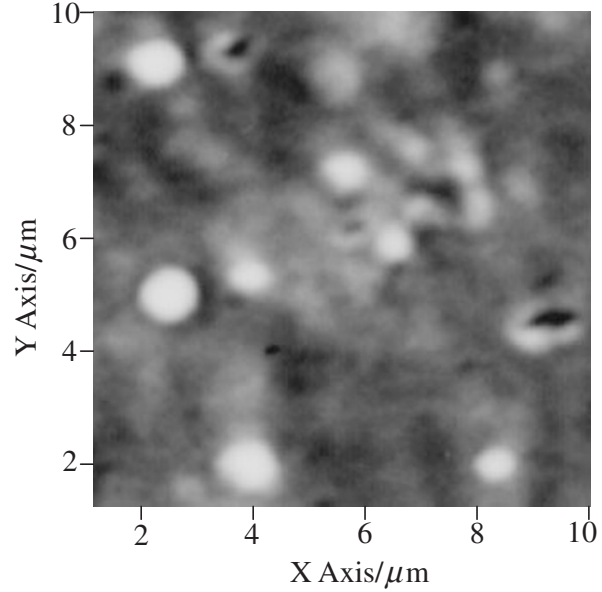

$\left(\mathrm{A}^{\prime}\right)$

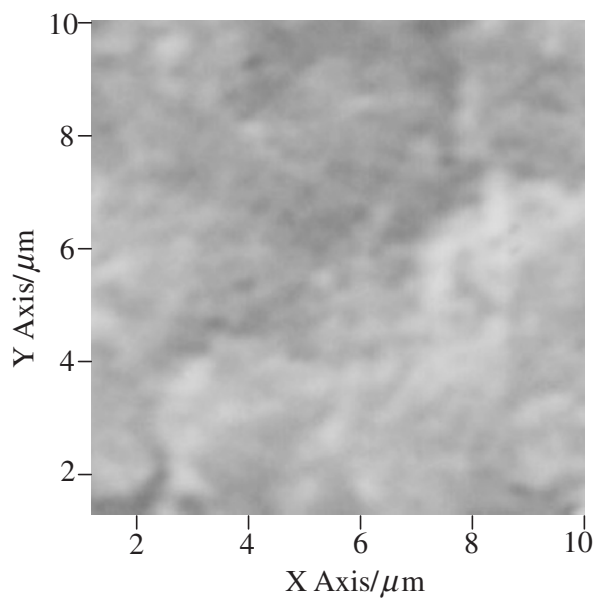

$\left(\mathrm{B}^{\prime}\right)$

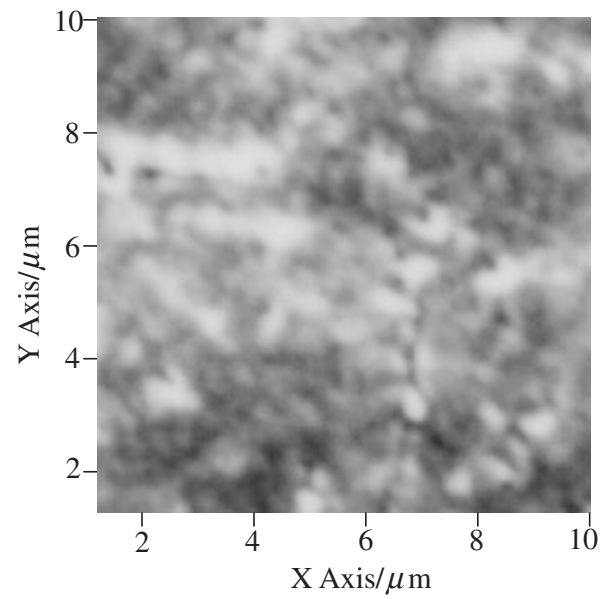

$\left(\mathrm{C}^{\prime}\right)$

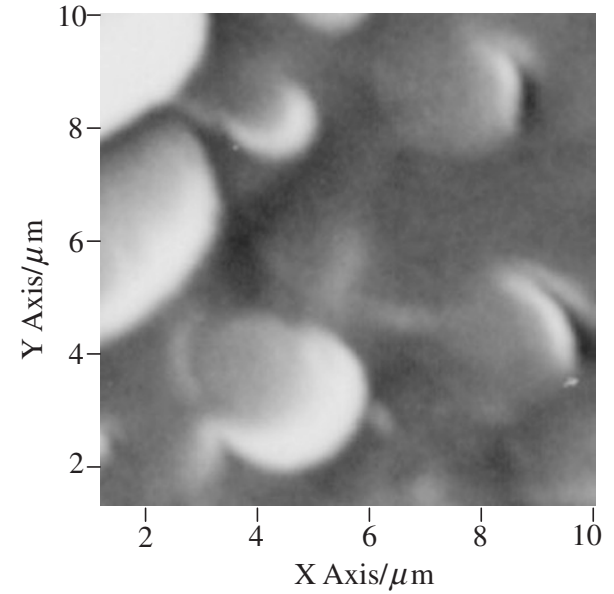

Figure 4. SEM images of $20 / 80$ and $80 / 20$ blends of PE and PP. A: HDPE/PP blends (20/80), A': HDPE/PP blends (80/20), B: LLDPE/PP blends (20/80), B': LLDPE/PP blends (80/20), C: MEPE/PP blends (20/80), C': MEPE/PP blends (80/20).

of $2 \theta$ ranges from direct beam to $40^{\circ}$. These patterns of the PEs and PP show that the (110) and (200) reflections of $\mathrm{PE}$ at 21.6 and $24.0^{\circ}$, and that the (110) and (040) reflections of PP at 14.0 and $16.8^{\circ}$. It can be seen from Figure 5 that the MEPE yields quite different X-ray diffraction patterns compared to the other kind of PEs. Since the crystallinity of MEPE is very low, its reflection peaks did not appear obviously. The WAXD curves of the blends are resolved to the following crystalline and amorphous peaks for $\mathrm{PE}$ and PP; PE(110), PE(200), PP(110), PP(040), a broad halo, and so on. It is hard to estimate the crystallinities for PE and PP in the blends, since the halo bands cannot be separated for each component correctly. 


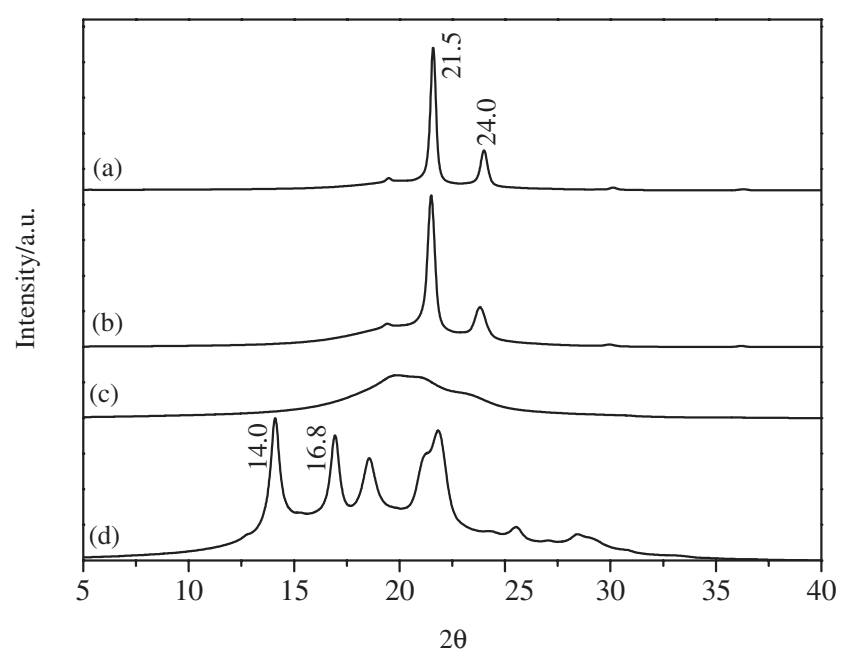

Figure 5. The curve resolution of a WAXD reflection pattern. (a): HDPE, (b): LLDPE, (c): MEPE, (d): PP.

Table III. FWHM values of PE and PP reflection peaks in WAXD data

\begin{tabular}{lrcccc}
\hline & \multirow{2}{*}{ PP contents } & \multicolumn{2}{c}{ PE } & \multicolumn{2}{c}{ PP } \\
\cline { 3 - 6 } & & 21.5 & 24.0 & 14.0 & 16.8 \\
\hline & 0 & 0.2961 & 0.3875 & - & - \\
HDPE/PP & 20 & 0.3127 & 0.4051 & 0.7829 & 0.3360 \\
systems & 40 & 0.3180 & 0.4204 & 0.5618 & 0.4009 \\
& 60 & 0.3447 & 0.4141 & 0.6245 & 0.4109 \\
& 80 & 0.3693 & 0.4167 & 0.5640 & 0.3909 \\
& 100 & - & - & 0.5013 & 0.3875 \\
\hline & 0 & 0.3871 & 0.6320 & - & - \\
LLDPE/PP & 20 & 0.4569 & 0.6445 & 0.5138 & 0.5672 \\
systems & 40 & 0.4548 & 0.6574 & 0.5098 & 0.4362 \\
& 60 & 0.4822 & 0.7395 & 0.5457 & 0.4355 \\
& 80 & 0.5142 & 0.7203 & 0.5304 & 0.4067 \\
& 100 & - & - & 0.5013 & 0.3875 \\
\hline & 0 & n.d. & n.d. & - & - \\
MEPE/PP & 20 & n.d. & n.d. & 0.6967 & 1.3475 \\
systems & 40 & n.d. & n.d. & 0.6459 & 0.8235 \\
& 60 & n.d. & n.d. & 0.5990 & 0.5430 \\
& 80 & n.d. & n.d. & 0.4466 & 0.4497 \\
& 100 & - & - & 0.5013 & 0.3875 \\
\hline & & & & n.d.: not & detected.
\end{tabular}

However, the values of full width at half maximum (FWHM) for each peak can be estimated from the resolved peaks. Thus, in order to evaluate the variation of the crystalline sizes for each polymer blend, the FWHM of the (110) and (200) reflection of PE, and the (110) and (040) reflection of PP are evaluated.

To estimate the FWHM intensity of the PE and PP reflection peaks they were analyzed by a curve-fitting method. In the cases of the HDPE/PP and LLDPE/PP blends, it can be seen from Table III that the FWHM of all the peaks of PE and PP change only slightly with the blending ratio. However, for the MEPE/PP
(A)

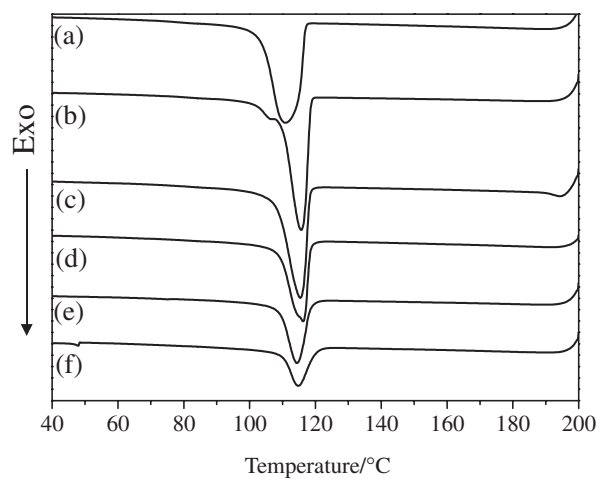

(B)

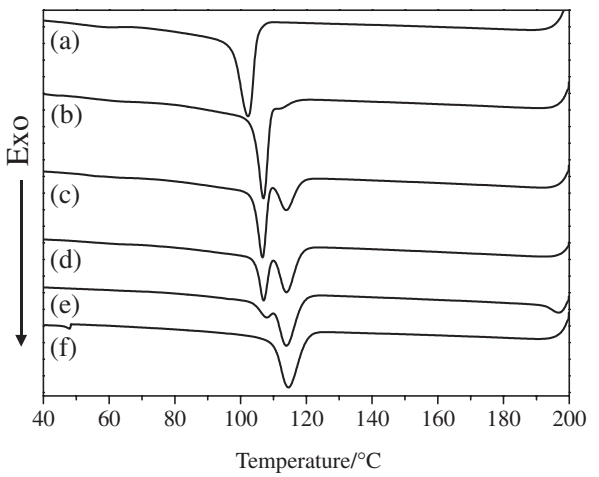

(C)

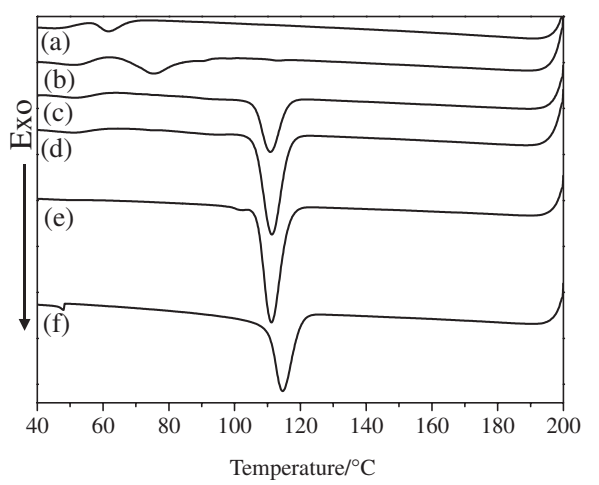

Figure 6. DSC scans during the cooling process of the different blends. A: HDPE/PP blends, B: LLDPE/PP blends, C: MEPE/PP blends. (a): PE, (b): 80/20 blend, (c): 60/40 blend, (d): 40/60 blend, (e): 20/80 blend, (f): PP.

blends, the FWHM of the reflection peaks of PP change obviously with the PP content (Table III). This means that the crystallization behavior of PP is affected by the MEPE component. As the concentration of MEPE is increased, the FWHM of the reflection peaks of PP becomes unclear because the PP peaks are almost hidden in the broad MEPE bands. It was rather difficult to estimate of the FWHM of the reflection peaks of MEPE because MEPE does not show a crystalline peak clearly in the WAXD patterns. Thus, the results for the MEPE/PP blends need further verification by other methods like DSC.

DSC

Figures $6 \mathrm{~A}, 6 \mathrm{~B}$, and $6 \mathrm{C}$ display the cooling processes observed in the DSC scans during the cooling 
(A)

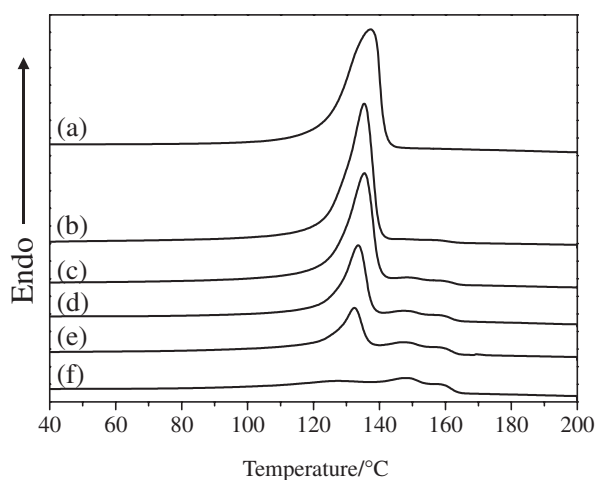

(B)

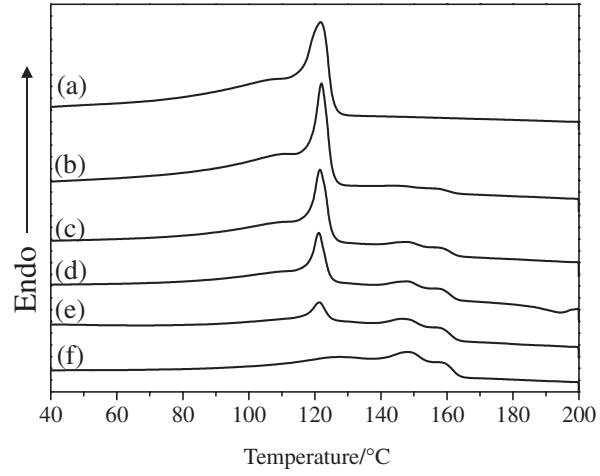

(C)

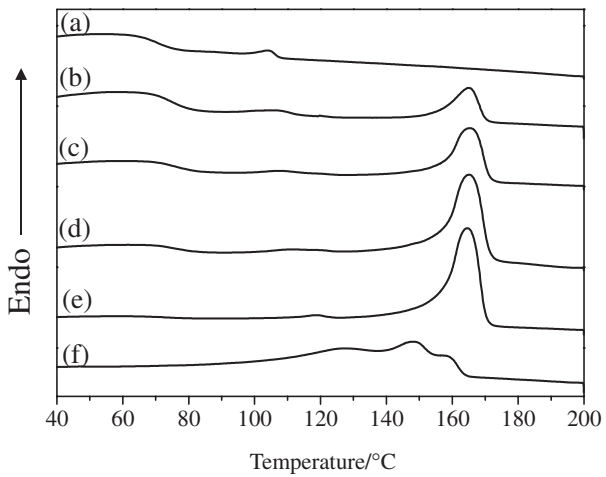

Figure 7. DSC scans during the heating process of each blend. A: HDPE/PP blends, B: LLDPE/PP blends, C: MEPE/ PP blends. (a): PE, (b): 80/20 blend, (c): $60 / 40$ blend, (d): 40/ 60 blend, (e): 20/80 blend, (f): PP.

of HDPE/PP, LLDPE/PP, and MEPE/PP blends, respectively. Figures 7A, 7B and 7C present the heating processes observed in the DSC scans during the heating of HDPE/PP, LLDPE/PP, and MEPE/PP blends, respectively. The crystallization and melting temperatures of PE and PP for all the blends are listed in Table IV. For the cooling processes, the DSC curves of all the blends show peaks arising from PE and PP. The crystallization peak of PP is observed at $120^{\circ} \mathrm{C}$ for each of the three blends. In the DSC curves of the HDPE/PP blends, the crystallization peaks of HDPE and PP appear almost at the same temperature $\left(120^{\circ} \mathrm{C}\right)$. Thus, it is difficult for these peaks to be distinguished into each peak. In the DSC curves of the LLDPE/PP blends, the peaks of LLDPE and PP appear at different temperatures, $109^{\circ} \mathrm{C}$ and $120^{\circ} \mathrm{C}$, respectively. Therefore, it is possible to distinguish
Table IV. Crystallization and melting temperature of PE and PP in the blends

\begin{tabular}{|c|c|c|c|c|c|}
\hline & \multirow{2}{*}{ PP contents } & \multicolumn{2}{|c|}{$T_{\mathrm{c}} /{ }^{\circ} \mathrm{C}$} & \multicolumn{2}{|c|}{$T_{\mathrm{m}} /{ }^{\circ} \mathrm{C}$} \\
\hline & & $\mathrm{PE}$ & PP & $\mathrm{PE}$ & $\mathrm{PP}$ \\
\hline \multirow{6}{*}{$\begin{array}{l}\text { HDPE/PP } \\
\text { systems }\end{array}$} & 0 & \multicolumn{2}{|c|}{ n.d. } & 134.6 & - \\
\hline & 20 & \multicolumn{2}{|c|}{121.0} & 134.7 & n.d. \\
\hline & 40 & \multicolumn{2}{|c|}{120.8} & 134.9 & 148.0 \\
\hline & 60 & \multicolumn{2}{|c|}{121.2} & 134.1 & 147.2 \\
\hline & 80 & \multicolumn{2}{|c|}{119.9} & 133.1 & 147.0 \\
\hline & 100 & \multicolumn{2}{|c|}{123.0} & - & 148.2 \\
\hline \multirow{6}{*}{$\begin{array}{l}\text { LLDPE/PP } \\
\text { systems }\end{array}$} & 0 & 108.9 & - & 122.5 & - \\
\hline & 20 & 109.2 & 118.7 & 121.1 & n.d. \\
\hline & 40 & 109.1 & 121.3 & 120.7 & 143.5 \\
\hline & 60 & 109.3 & 120.1 & 120.9 & 147.5 \\
\hline & 80 & 109.5 & 120.2 & 120.8 & 146.2 \\
\hline & 100 & - & 123.0 & - & 148.2 \\
\hline \multirow{6}{*}{$\begin{array}{l}\text { MEPE/PP } \\
\text { systems }\end{array}$} & 0 & n.d. & - & n.d. & - \\
\hline & 20 & n.d. & n.d. & n.d. & 165.1 \\
\hline & 40 & n.d. & 118.6 & n.d. & 165.3 \\
\hline & 60 & n.d. & 119.1 & n.d. & 164.9 \\
\hline & 80 & n.d. & 119.7 & n.d. & 164.6 \\
\hline & 100 & - & 123.0 & - & 148.2 \\
\hline
\end{tabular}

each peak separately. The crystallinity of MEPE is so low that the crystallization peak of MEPE cannot be observed clearly in the DSC curve. The PP crystallization temperatures of three kinds of the blends go down a little to low temperature (from 123 to $120^{\circ} \mathrm{C}$ ) as compared with pure PP. On the other hand, for the heating processes, the PE fusion peaks of HDPE/PP and LLDPE/PP blends appear clearly but that of MEPE/PP do not. Although the PP fusion peaks appear for HDPE/PP and LLDPE/PP blends, their peaks are week and broad. There are three fusion peaks of pure PP at least at 129,148 , and $162^{\circ} \mathrm{C}$. These three fusion peaks suggest that different crystalline structures exist in PP crystal or that PP is melted and recrystallized in the heating process. Although the peak at $148^{\circ} \mathrm{C}$ is the strongest among these peaks, its intensity is not so strong. Therefore, it is difficult to display both PE and PP fusion peaks at the same scale. However, the enthalpy of PP fusion peak can be estimated in the blends except for the PP-rich blends. The peak of HDPE is observed at $134{ }^{\circ} \mathrm{C}$, and that of LLDPE is observed at $121^{\circ} \mathrm{C}$. The melting temperatures of HDPE and LLDPE change little with the blend ratio. On the other hand, the melting temperature of MEPE cannot be detected clearly because of its low crystallinity. These results indicate that in the HDPE/PP and LLDPE/PP blends the interactions between PE and PP are rather weak and that the interactions do not cause a significant change in the crystallization temperature. In the case of MEPE/PP blends, fusion peaks are observed as broad bands at $165^{\circ} \mathrm{C}$. The 
Table V. Enthalpy of crystallization and fusion peaks of PE and PP in the blends

\begin{tabular}{|c|c|c|c|c|c|}
\hline & \multirow{2}{*}{ PP contents } & \multicolumn{2}{|c|}{$\Delta H_{\mathrm{c}} / \mathrm{J} \mathrm{g}^{-1}$} & \multicolumn{2}{|c|}{$\Delta H_{\mathrm{m}} / \mathrm{J} \mathrm{g}^{-1}$} \\
\hline & & $\mathrm{PE}$ & PP & $\mathrm{PE}$ & PP \\
\hline \multirow{6}{*}{$\begin{array}{l}\text { HDPE/PP } \\
\text { systems }\end{array}$} & 0 & \multicolumn{2}{|c|}{ n.d. } & 216.94 & - \\
\hline & 20 & \multicolumn{2}{|c|}{-329.96} & \multicolumn{2}{|c|}{280.03} \\
\hline & 40 & \multicolumn{2}{|c|}{-309.98} & \multicolumn{2}{|c|}{239.87} \\
\hline & 60 & \multicolumn{2}{|c|}{-279.97} & \multicolumn{2}{|c|}{191.77} \\
\hline & 80 & \multicolumn{2}{|c|}{-214.00} & \multicolumn{2}{|c|}{120.87} \\
\hline & 100 & \multicolumn{2}{|c|}{ n.d. } & - & 26.00 \\
\hline \multirow{6}{*}{$\begin{array}{l}\text { LLDPE/PP } \\
\text { systems }\end{array}$} & 0 & n.d. & - & 128.63 & - \\
\hline & 20 & -122.70 & -10.23 & 104.66 & 9.38 \\
\hline & 40 & -96.22 & -34.12 & 77.73 & 15.12 \\
\hline & 60 & -58.37 & -53.23 & 50.85 & 23.76 \\
\hline & 80 & -18.16 & -73.94 & 20.33 & 31.44 \\
\hline & 100 & - & -112.52 & - & 26.00 \\
\hline \multirow{6}{*}{$\begin{array}{l}\text { MEPE/PP } \\
\text { systems }\end{array}$} & 0 & n.d. & - & n.d. & - \\
\hline & 20 & n.d. & n.d. & n.d. & 26.76 \\
\hline & 40 & n.d. & -58.13 & n.d. & 45.64 \\
\hline & 60 & n.d. & -104.51 & n.d. & 77.45 \\
\hline & 80 & n.d. & -133.66 & n.d. & 103.88 \\
\hline & 100 & - & -112.52 & - & 26.00 \\
\hline
\end{tabular}

shape and temperature of these peaks are different from those of pure MEPE and PP fusion peaks. However, the intensities of these peaks change linearly with the blend ratio. Therefore, these fusion peaks are assigned to the PP fusion peak. The shift of PP fusion peak means that the crystallization behavior of PP is affected by the MEPE component.

The enthalpy of crystallization and fusion, as characterized by the DSC peak areas in the cooling and heating curves, are summarized in Table $\mathrm{V}$ for the HDPE/PP, LLDPE/PP, and MEPE/PP blends, respectively. In the HDPE/PP blends, because of the above reason the crystallization enthalpy of each component cannot be estimated. The fusion enthalpy of HDPE and PP also cannot be estimated separately because of the partial overlap between their fusion peaks. The fusion peak of HDPE is observed at $134^{\circ} \mathrm{C}$ and that of PP appearing at the lowest temperature is $129^{\circ} \mathrm{C}$. In the LLDPE/PP blends, both the crystallization and fusion enthalpy of LLDPE and PP change linearly with the blend ratio in the LLDPE/PP blends. The fusion enthalpy of LLDPE and crystallization enthalpy of PP go down corresponding to the PP content. On the other hand, the crystallization enthalpy of LLDPE and fusion enthalpy of PP go up corresponding to the PP content. For the MEPE/PP blends, both the crystallization and fusion enthalpy of PP also show a linear change with the blend ratio. However, the $80 / 20$ blend does not have the crystallization peak of PP, and thus at this blend ratio there is no enthalpy value in the Table $\mathrm{V}$. The fusion enthalpy of MEPE cannot be estimated, because the crystallinity of MEPE is so low that the fusion peak of MEPE cannot be observed clearly in the DSC curve. The fusion and crystallization enthalpy of PP go up and go down corresponding to the PP content, respectively. The enthalpy of crystallization and fusion of PP in MEPE/PP blends are larger than in the other kinds of blends. As shown in Raman mapping images and SEM images, MEPE/PP blends have "sea-island" structure. Thus, it is easy for PP to crystallize in the blends.

\section{CONCLUSION}

This study has investigated the differences in the molecular structure, crystallinity and morphology among the HDPE/PP, LLDPE/PP and MEPE/PP blends by using Raman mapping, SEM, WAXD and DSC. The following conclusions can be reached from the present study.

1. The Raman mapping images and the SEM images have shown that the MEPE/PP blends with the large MFI ratio have different dispersibility behavior compared to the HDPE/PP and LLDPE/PP blends with the small MFI ratios. The MEPE/PP blends have a typical "sea-island" structure while the other blends have homogeneous structures.

2. The HDPE/PP and LLDPE/PP blends show sharper X-ray diffraction patterns than the MEPE/PP blends. The FWHM of HDPE/PP and LLDPE/PP blends changes only slightly with a variation in the blend ratio but that of MEPE/PP changes significantly. This suggests that MEPE affects the crystallization of PP in the MEPE/PP blends.

3. The DSC crystallization and fusion both peak areas of the HDPE/PP, LLDPE/PP, and MEPE/PP blends change linearly as a function of blending ratio. Moreover, the crystallization temperature of each component is constant in the three kinds of blends but that of PP goes down little as compared with that of pure PP. The melting temperatures of HDPE, LLDPE, and PP in the HDPE/PP and LLDPE/PP blends do not change with the blending ratios, but that of PP in the MEPE/PP blends goes up with increase in the PP contents. The enthalpies of fusion peak of PP are also larger than those of neat PP. These mean that MEPE has significant influence on the crystallization of PP.

The blends of HDPE/PP and LLDPE/PP showed almost the same trends in all the measurement methods used in the present study. The WAXD and DSC results have suggested that there is little interaction between PP and PE in the HDPE/PP and LLDPE/ 
PP blends. Each component in the HDPE/PP and LLDPE/PP blends is crystallized independently, so that the interaction between HDPE (LLDPE) and PP is very weak. On the other hand, the MEPE/PP blends showed that unique FWHM changes of PP in the WAXD pattern with the blending ratio and that the enhancement and shift of the enthalpy and temperature of the PP fusion peak. In the polymer blends of PE and PP, the amorphous parts of PE play an important role in the crystallization process of blends of each component.

\section{REFERENCES}

1. A. J. Peacock, "Handbook of Polyethylene," Marcel Dekker, New York, 2000.

2. "Polypropylene Handbook," E. P. Moore, Jr., Ed., Carl Hanser, Verlag, Munich, 1996.

3. J. Huang, Z. Feng, H. Wang, Y. Qian, J. Sun, Y. Xu, W. Chen, and G. Zheng, J. Mol. Catal., 189, 187 (2002).

4. E. Kolodka, W. J. Wang, S. Zhu, and A. Hamielec, J. Appl. Polym. Sci., 92, 307 (2004).

5. H. Al-Hussein, G. R. Davies, and I. M. Ward, Polymer, 42, 3679 (2001).

6. M. J. Cran and S. W. Bigger, Appl. Spectrosc., 57, 928 (2003).

7. U. Niebergall, J. Bohse, B. L. Shurmann, S. Seidler, and W. Grellmann, Polym. Eng. Sci., 39, 1109 (1999).

8. Q. Du and L. Wang, J. Polym. Sci., Polym. Phys. Ed., 27, 581 (1989).

9. M. M. Dumoulin and P. J. Carreau, Polym. Eng. Sci., 27, 1627 (1987).

10. P. Schmidt, J. Baldrian, J. Scudla, J. Dybal, M. Raab, and K. J. Eichhorn, Polymer, 42, 5321 (2001).

11. A. C. Y. Wong and F. Lam, Polym. Test., 21, 691 (2002).

12. J. Li, R. A. Shanks, and Y. Long, J. Appl. Polym. Sci., 87, 1179 (2003).

13. J. Finlay, M. J. Hill, P. J. Barham, K. Byrne, and A. Woogara, J. Polym. Sci., Part B: Polym. Phys., 41, 1384 (2003).

14. J. Li, R. A. Shanks, R. H. Olley, and G. R. Greemway, Polymer, 42, 7685 (2001).
15. Z. Bartczak, A. Galeski, and M. Pracella, Polymer, 27, 537 (1986).

16. Y. Wang, B. Na, Q. Fu, and Y. Men, Polymer, 45, 207 (2004).

17. B. Lotz and J. C. Wittmann, J. Polym. Sci., Part B: Polym. Phys., 25, 1079 (1987).

18. O. F. Noel III and J. F. Carley, Polym. Eng. Sci., 24, 488 (1984).

19. P. J. Hendra and J. K. Agbenyega, "The Raman Spectra of Polymers," John Wiley \& Sons, Chichester, Sections $D_{1}$ and $\mathrm{E}_{2}, 1993$.

20. G. R. Strobl and W. Hagedorn, J. Polym. Sci., Part B: Polym. Phys., 16, 1181 (1978).

21. A. Garton, D. N. Batchelder, and C. Cheng, Appl. Spectrosc., 47, 922 (1993).

22. T. Furukawa, M. Watari, H. W. Siesler, and Y. Ozaki, J. Appl. Polym. Sci., 87, 616 (2003).

23. K. Tashiro, S. Kariyo, A. Nishimori, T. Fujii, S. Saragai, S. Nakamoto, T. Kawaguchi, A. Matsumoto, and O. Rangsiman, J. Polym. Sci., Part B: Polym. Phys., 40, 495 (2002).

24. A. Gupper, P. Wilhelm, M. Schmied, S. G. Kazarian, K. L. Chan, and J. Reubner, Appl. Spectrosc., 56, 1515 (2002).

25. H. Sato, S. Sasao, K. Matsukawa, Y. Kita, H. Yamaguchi, H. W. Siesler, and Y. Ozaki, Macromol. Chem. Phys., 204, 1351 (2003).

26. H. Sato, S. Sasao, K. Matsukawa, Y. Kita, T. Ikeda, H. Tashiro, and Y. Ozaki, Appl. Spectrosc., 56, 1038 (2002).

27. M. F. S. Lima, M. A. Z. Vasconcellos, and D. Samios, J. Polym. Sci., Part B: Polym. Phys., 40, 896 (2002).

28. L. Markwort and B. Kip, J. Appl. Polym. Sci., 61, 231 (1996).

29. R. Appel, T. W. Zerda, and W. H. Waddell, Appl. Spectrosc., 54, 1559 (2000).

30. S. L. Quintana, P. Schmidt, J. Dybal, J. Kratochvil, J. M. Pastor, and J. C. Merino, Polymer, 43, 5187 (2002).

31. R. L. Morgan, M. J. Hill, P. J. Barham, A. van der Pol, B. J. Kip, R. Ottjes, and J. van Ruiten, Polymer, 42, 2121 (2001).

32. T. Sundell, H. Fagerholm, and H. Crozier, Polymer, 37, 3227 (1996).

33. M. C. Tobin, J. Phys. Chem., 64, 216 (1960). 